OPEN ACCESS

Edited by:

David Z. Qian

Oregon Health and Science University,

United States

Reviewed by:

Maja Cemazar

Institute of Oncology

Ljubljana, Slovenia

Gage Redler,

Moffitt Cancer Center, United States

Hironobu Yasui,

Hokkaido University, Japan

Joseph P. Y. Kao,

University of Maryland, United States

*Correspondence:

Philip E. Schane

philip.e.schaner@hitchcock.org

Specialty section:

This article was submitted to Molecular and Cellular Oncology,

a section of the journal

Frontiers in Oncology

Received: 17 June 2020 Accepted: 21 September 2020

Published: 27 October 2020

Citation:

Schaner PE, Pettus JR, Flood $A B$, Williams $B B$, Jarvis $L A$, Chen $E Y$

Pastel DA, Zuurbier RA, diFlorio-Alexander RM, Swartz HM and Kuppusamy P (2020) OxyChip Implantation and Subsequent Electron Paramagnetic Resonance Oximetry in Human Tumors Is Safe and Feasible:

First Experience in 24 Patients.

Front. Oncol. 10:572060.

doi: 10.3389/fonc. 2020.572060

\section{OxyChip Implantation and Subsequent Electron Paramagnetic Resonance Oximetry in Human Tumors Is Safe and Feasible: First Experience in 24 Patients}

\author{
Philip E. Schaner 1,2,3*, Jason R. Pettus ${ }^{1,2,3,4}$, Ann Barry Flood ${ }^{2,3,5}$, Benjamin B. Williams , $^{1,2,3,}$, \\ Lesley A. Jarvis ${ }^{1,2,3}$, Eunice Y. Chen ${ }^{2,3,6}$, David A. Pastel ${ }^{2,3,5}$, Rebecca A. Zuurbier $^{2,3,5}$, \\ Roberta M. diFlorio-Alexander ${ }^{2,3,5}$, Harold M. Swartz ${ }^{1,2,3,5}$ and Periannan Kuppusamy ${ }^{1,2,3,5}$ \\ ${ }^{1}$ Department of Medicine, Dartmouth Hitchcock Medical Center, Lebanon, NH, United States, ${ }^{2}$ Geisel School of Medicine, \\ Dartmouth College, Hanover, NH, United States, ${ }^{3}$ Norris Cotton Cancer Center, Lebanon, NH, United States, ${ }^{4}$ Department \\ of Pathology, Dartmouth Hitchcock Medical Center, Lebanon, NH, United States, ${ }^{5}$ Department of Radiology, Dartmouth \\ Hitchcock Medical Center, Lebanon, NH, United States, ${ }^{6}$ Department of Surgery, Dartmouth Hitchcock Medical Center, \\ Lebanon, NH, United States
}

Introduction: Tumor hypoxia confers both a poor prognosis and increased resistance to oncologic therapies, and therefore, hypoxia modification with reliable oxygen profiling during anticancer treatment is desirable. The OxyChip is an implantable oxygen sensor that can detect tumor oxygen levels using electron paramagnetic resonance (EPR) oximetry. We report initial safety and feasibility outcomes after OxyChip implantation in a first-in-humans clinical trial (NCT02706197, www.clinicaltrials.gov).

Materials and Methods: Twenty-four patients were enrolled. Eligible patients had a tumor $\leq 3 \mathrm{~cm}$ from the skin surface with planned surgical resection as part of standard-of-care therapy. Most patients had a squamous cell carcinoma of the skin (33\%) or a breast malignancy (33\%). After an initial cohort of six patients who received surgery alone, eligibility was expanded to patients receiving either chemotherapy or radiotherapy prior to surgical resection. The OxyChip was implanted into the tumor using an 18-G needle; a subset of patients had ultrasound-guided implantation. Electron paramagnetic resonance oximetry was carried out using a custom-built clinical EPR scanner. Patients were evaluated for associated toxicity using the Common Terminology Criteria for Adverse Events (CTCAE); evaluations started immediately after OxyChip placement, occurred during every EPR oximetry measurement, and continued periodically after removal. The OxyChip was removed during standard-of-care surgery, and pathologic analysis of the tissue surrounding the OxyChip was performed.

Results: Eighteen patients received surgery alone, while five underwent chemotherapy and one underwent radiotherapy prior to surgery. No unanticipated serious adverse device events occurred. The maximum severity of any adverse event as graded by the CTCAE was 1 (least severe), and all were related to events typically associated with implantation. After surgical resection, $45 \%$ of the patients had no histopathologic findings 
specifically associated with the OxyChip. All tissue pathology was "anticipated" excepting a patient with greater than expected inflammatory findings, which was assessed to be related to the tumor as opposed to the OxyChip.

Conclusion: This report of the first-in-humans trial of OxyChip implantation and EPR oximetry demonstrated no significant clinical pathology or unanticipated serious adverse device events. Use of the OxyChip in the clinic was thus safe and feasible.

Keywords: OxyChip, hypoxia, electron paramagnetic resonance, oximetry, clinical trial, safety, feasibility

\section{INTRODUCTION}

Tumor hypoxia is associated with a poor prognosis as well as increased resistance to oncologic therapies, including radiotherapy and chemotherapy, in many malignancies (15). A multitude of clinical trials have attempted to modify tumor hypoxia in order to improve therapeutic efficacy; for example, a meta-analysis of trials investigating hypoxia modification during radiotherapy in head-and-neck squamous cell carcinomas demonstrated a significant improvement with hypoxia modification in locoregional control [odds ratio (OR) 0.71 ], disease-specific survival (OR 0.73 ), and overall survival (OR 0.87) (6). However, routine hypoxia modification in the clinic has generally not been adopted as standard of care. In part, this is due to the failure to demonstrate an overall survival benefit in modern Phase III trials; it has been suggested that this outcome is related to an inability to appropriately select patients for targeted hypoxia interventions (7). Adoption has also been hampered by difficulties associated with the clinical implementation of hypoxia modification in a straightforward, cost-effective manner. Electron paramagnetic resonance (EPR) oximetry has the potential to address these needs by facilitating appropriate patient selection prior to oxygen modification, providing real-time feedback as to the success of oxygen modification, and functioning seamlessly within the clinical workflow.

EPR oximetry has the potential to allow rapid, repeated assessments of hypoxia in the clinical setting (8). EPR oximetry relies on a paramagnetic probe implanted within a tissue of interest to measure the surrounding partial pressure of oxygen $\left(\mathrm{pO}_{2}\right)$. Subsequent oxygen measurements are obtained noninvasively by placing a surface coil of about $10 \mathrm{~mm}$ in diameter over the probe. $\mathrm{pO}_{2}$ measurements are then obtained in real time as often as desired (8).

EPR oximetry in humans has thus far been conducted using probes composed of ink particulates; these probes are limited in that they can only measure oxygen if placed within a few $\mathrm{mm}$ of the skin surface $(9,10)$. Although ink particulates are tolerated well, this depth limitation hampers their clinical utility vis a vis human malignancies (11). In contrast, the OxyChip probe, a small paramagnetic oxygen sensor composed of oxygen-sensing lithium octa- $n$-butoxynaphthalocyanine (LiNc$\mathrm{BuO}$ ) crystals embedded in a biocompatible polymer (12), can measure $\mathrm{pO}_{2}$ up to a depth of at least $1.5 \mathrm{~cm}$. Here, we report initial data from a first-in-humans trial on the feasibility of OxyChip implantation and EPR oximetry, clinical adverse events associated with OxyChip implantation, and the histopathology associated with the presence of the OxyChip in human tissues. Data pertaining to the primary endpoint of the trial, safety, are reported here. Data pertaining to the secondary endpoint, EPR oximetry measurements, will be reported separately.

\section{MATERIALS AND METHODS}

All patients were enrolled in the clinical trial NCT02706197: Oxygen Measurements in Subcutaneous Tumors by EPR Oximetry Using OxyChip. This study was carried out in accordance with US and international standards of Good Clinical Practice (FDA Title 21 part 312 and International Conference on Harmonization guidelines). The Institutional Review Boards (IRBs) at Dartmouth College and DartmouthHitchcock Medical Center approved the protocol (IRB Study 28499). All subjects gave written informed consent in accordance with the Declaration of Helsinki and as approved by these IRBs and the Food and Drug Administration. Eligible patients were 18 years or older, not pregnant, had no contraindications to exposure to a magnetic field, had a tumor $\leq 3 \mathrm{~cm}$ from the skin surface (benign tumors, as well as malignancies, were eligible), had not had radiotherapy to the tumor prior to implantation, and were slated to receive surgical resection of their tumor at least 3 days after implantation as part of standard-of-care therapy. An initial cohort of six patients who received surgery alone after OxyChip implantation was evaluated for safety and toxicity endpoints. After this evaluation demonstrated no significant safety or toxicity findings, a second cohort opened, in which patients were allowed to have either chemotherapy or radiotherapy prior to surgical resection, but not both concurrently. The OxyChip, LiNc$\mathrm{BuO}$ crystals embedded in polydimethylsiloxane elastomer, was characterized for human applications according to ISO 1099312:2012 guidelines (13). Each clinical OxyChip was fabricated in-house to be $\sim 5 \mathrm{~mm}$ in length and $0.6 \mathrm{~mm}$ in width (Figure 1A) and was sterilized prior to implantation using steam sterilization with appropriate biological and chemical indicators. At the time of implantation, the OxyChip was placed within an 18-G brachytherapy needle, the needle was inserted into the tumor under local anesthesia (1\% lidocaine), and the OxyChip was deployed under sterile conditions (Figure 1B). Ultrasound image guidance to direct needle placement was used in a subset of patients (Figures 1C,D). Ultrasound guidance was initially 


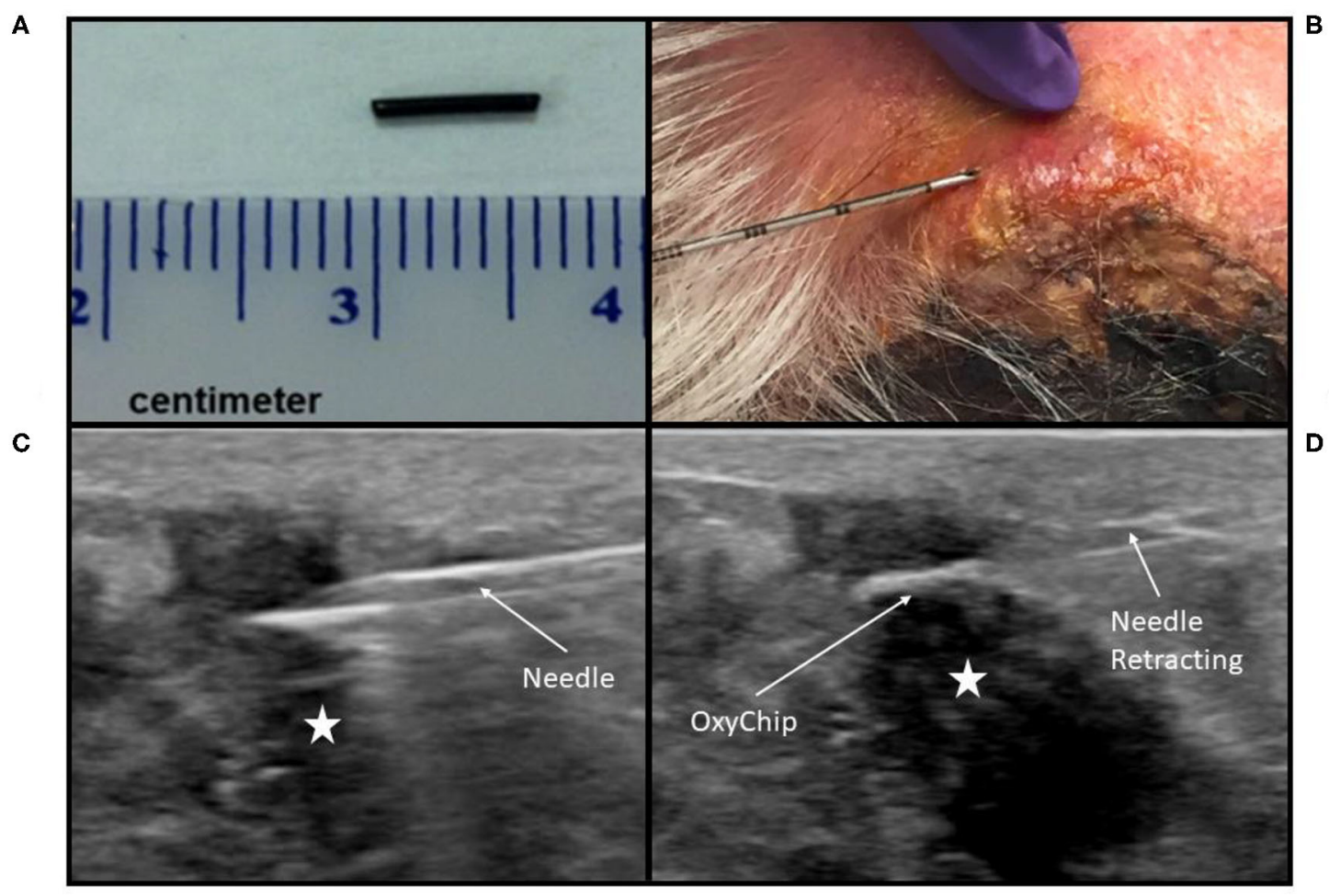

FIGURE 1 | OxyChip implantation. (A) OxyChip prior to implantation. (B) Implantation needle, with the OxyChip inside, being inserted into a squamous cell carcinoma of the skin. Due to the depth and size of the malignancy, no image guidance was used, and depth of insertion was determined using needle graduations. (C,D) Implantation under ultrasound guidance into a breast malignancy. (C) The implantation needle, with OxyChip inside, being inserted into the malignancy (hypoechoic area labeled with a star) prior to OxyChip deployment. (D) OxyChip after deployment within the malignancy (hypoechoic area labeled with a star). The needle is being retracted after deployment of the OxyChip.

used for deeper tumors or superficial tumors where there was concern on the part of the investigators that deployment might occur outside the tumor. After results indicated OxyChip deployment outside of tumors in a number of superficial sites (see Results), ultrasound guidance was routinely used for most implantations. Implantations occurred either in the clinic or in a dedicated procedural suite depending on the need for image guidance. After implantation, patients were evaluated for associated toxicity by a physician immediately after OxyChip placement, at all EPR oximetry measurements, and, if the patient received chemotherapy, at all chemotherapy administration appointments. Patients were also evaluated within 2 weeks of surgical resection of the tumor and monitored until a year after device removal. Adverse events were scored using the Common Terminology Criteria for Adverse Events (CTCAE) $\mathrm{v} 4.0$ (14).

EPR oximetry was carried out using the clinical EPR scanner (8). Patients were positioned supine on a gurney within the magnetic field and the EPR resonator loop was placed over the site of OxyChip implantation. Ultrasound was used in some patients to locate the OxyChip prior to resonator placement. EPR oximetry measurements were performed per protocol with the patient breathing room air, followed by a period of oxygen inhalation using a non-rebreather mask with $100 \%$ oxygen at a flow rate of $15 \mathrm{~L} / \mathrm{min}$, and then breathing room air again; all three measurement periods were planned for $10 \mathrm{~min}$, for an anticipated total of $30 \mathrm{~min}$. Not all patients completed all measurements, due primarily to logistical or technical considerations (e.g., the patient had a limited time for measurements, or the OxyChip was not found) as opposed to problems tolerating EPR measurements. Measurement sessions were repeated on multiple days as often as the patient was willing and available at the clinic. Patient-reported outcomes were assessed via a questionnaire that was administered to amenable patients $(n=4)$ after the initial EPR oximetry session. Patients were queried using a subjective scale with respect to the implantation as well as the experience of EPR oximetry measurements. The post-measurement questionnaire was considered to be an optional part of the trial, to be added at the discretion of the staff when appropriate. For a variety of reasons, most patients were not invited to complete the questionnaire; for example, in many patients it was felt they did not have enough time to complete the questionnaire due to medical appointments immediately after their EPR oximetry session.

The OxyChip was removed as part of the en-bloc tumor resection during standard-of-care surgery; no OxyChips were removed separately from the main tumor specimen. After 
TABLE 1 | Patient characteristics, clinical adverse events, and pathologic findings associated with OxyChip implantation.

\begin{tabular}{|c|c|c|c|c|c|c|c|c|c|c|c|}
\hline Patient & Age & Sex & Diagnosis & $\begin{array}{l}\text { Location of } \\
\text { OxyChip } \\
\text { implantation }\end{array}$ & $\begin{array}{l}\text { US } \\
\text { guidance }\end{array}$ & $\begin{array}{l}\text { Treatment prior } \\
\text { to OxyChip } \\
\text { removal }\end{array}$ & $\begin{array}{l}\text { Duration } \\
\text { of } \\
\text { implant } \\
\text { (days) }\end{array}$ & $\operatorname{Max} A E$ & Description AE & $\begin{array}{l}\text { Location of OxyChip on } \\
\text { microscopic evaluation }\end{array}$ & $\begin{array}{l}\text { Pathologic findings } \\
\text { associated with OxyChip }\end{array}$ \\
\hline 1 & 51 & $\mathrm{~F}$ & Lipoma & $\begin{array}{l}\text { Upper left back, } \\
\text { subcutaneous }\end{array}$ & $\mathrm{N}$ & None & 5 & 0 & NA & $\begin{array}{l}\text { Not within tumor; within } \\
\text { superficial fascia of } \\
\text { subcutaneous mass }\end{array}$ & $\begin{array}{l}\text { Mild macrophage } \\
\text { pre-dominant chronic } \\
\text { inflammatory reaction at } \\
\text { needle site }\end{array}$ \\
\hline 2 & 69 & $\mathrm{~F}$ & Melanoma & $\begin{array}{l}\text { Left anterior tibia, } \\
\text { skin }\end{array}$ & $\mathrm{N}$ & None & 4 & 1 & $\begin{array}{l}\text { Minor bleeding from } \\
\text { implantation needle }\end{array}$ & Within tumor & $\begin{array}{l}\text { Minor hemorrhage at site of } \\
\text { injection }\end{array}$ \\
\hline 3 & 61 & M & SCC Skin & $\begin{array}{l}\text { Left nasal dorsum, } \\
\text { skin }\end{array}$ & N & None & 32 & 0 & NA & Within tumor & $\begin{array}{l}\text { Mild macrophage and } \\
\text { foreign body type giant cell } \\
\text { reaction at OxyChip site }\end{array}$ \\
\hline 4 & 77 & M & Melanoma & Scalp, skin & $\mathrm{N}$ & None & 5 & 1 & Pruritis, scalp & Within tumor & $\begin{array}{l}\text { Tumor necrosis and mild } \\
\text { hemorrhage immediately } \\
\text { adjacent to injection site }\end{array}$ \\
\hline 5 & 69 & M & $\mathrm{BCC}$ & $\begin{array}{l}\text { Left temporal } \\
\text { scalp, skin }\end{array}$ & N & None & 33 & 1 & Pruritis & Within tumor & $\begin{array}{l}\text { Minor focal hemorrhage } \\
\text { seen adjacent to the deep } \\
\text { margin. Very focal collection } \\
\text { of macrophages. }\end{array}$ \\
\hline 6 & 63 & M & SCC Skin & $\begin{array}{l}\text { Scalp, posterior } \\
\text { superior, skin }\end{array}$ & $\mathrm{N}$ & None & Unk & 0 & NA & $\begin{array}{l}\text { Not found, presumed lost } \\
\text { prior to surgery due to } \\
\text { rapidly progressive tumor } \\
\text { necrosis }\end{array}$ & NA \\
\hline 7 & 61 & M & SCC Skin & $\begin{array}{l}\text { Right posterior } \\
\text { triangle neck, } \\
\text { subcutaneous } \\
\text { mass }\end{array}$ & $N$ & None & 30 & 1 & Discomfort at surgical site & $\begin{array}{l}\text { Outside of and adjacent to } \\
\text { tumor within dermis }\end{array}$ & $\begin{array}{l}\text { Focal disrupted tissue at } \\
\text { edge of tumor with mild } \\
\text { non-specific chronic } \\
\text { inflammation }\end{array}$ \\
\hline 8 & 56 & M & FTC & Thyroid & $\mathrm{N}$ & None & 47 & 0 & NA & Within tumor & No histologic response seen \\
\hline 9 & 72 & $\mathrm{~F}$ & SCC Skin & $\begin{array}{l}\text { Frontal scalp, left, } \\
\text { skin }\end{array}$ & $\mathrm{N}$ & None & 7 & 0 & NA & Within tumor & No histologic response seen \\
\hline 10 & 70 & M & SCC Skin & $\begin{array}{l}\text { Infraorbital cheek, } \\
\text { left, subcutaneous }\end{array}$ & $\mathrm{N}$ & None & 25 & 1 & $\begin{array}{l}\text { Minor bleeding from } \\
\text { implantation needle }\end{array}$ & $\begin{array}{l}\text { Adjacent to tumor, but not } \\
\text { within tumor; } 0.4 \mathrm{~cm} \text { from } \\
\text { tumor margin }\end{array}$ & Focal organizing fat necrosis \\
\hline 11 & 78 & M & SCC Skin & $\begin{array}{l}\text { Right temporal } \\
\text { scalp. Skin }\end{array}$ & $\mathrm{N}$ & None & 27 & 1 & $\begin{array}{l}\text { Minor bleeding from } \\
\text { implantation needle }\end{array}$ & Within tumor & No histologic response seen \\
\hline 12 & 83 & M & SCC Skin & $\begin{array}{l}\text { Right neck, level II } \\
\text { lymph node }\end{array}$ & $\mathrm{N}$ & None & 22 & 1 & $\begin{array}{l}\text { Minor bleeding from } \\
\text { implantation needle. Mild } \\
\text { bruising. }\end{array}$ & Within tumor & No comment \\
\hline 13 & 42 & $\mathrm{~F}$ & IDC & Right breast & Y & None & 10 & 1 & $\begin{array}{l}\text { Minimal bleeding associated } \\
\text { with implantation. Mild } \\
\text { bruising at needle insertion } \\
\text { site. }\end{array}$ & Within tumor & No histologic response seen \\
\hline
\end{tabular}


TABLE 1 | Continued

\begin{tabular}{|c|c|c|c|c|c|c|c|c|c|c|c|}
\hline Patient & Age & Sex & Diagnosis & $\begin{array}{l}\text { Location of } \\
\text { OxyChip } \\
\text { implantation }\end{array}$ & $\begin{array}{l}\text { US } \\
\text { guidance }\end{array}$ & $\begin{array}{l}\text { Treatment prior } \\
\text { to OxyChip } \\
\text { removal }\end{array}$ & $\begin{array}{l}\text { Duration } \\
\text { of } \\
\text { implant } \\
\text { (days) }\end{array}$ & Max AE & Description AE & $\begin{array}{l}\text { Location of OxyChip on } \\
\text { microscopic evaluation }\end{array}$ & $\begin{array}{l}\text { Pathologic findings } \\
\text { associated with OxyChip }\end{array}$ \\
\hline 14 & 48 & $\mathrm{~F}$ & IDC & Left breast & Y & None & 13 & 1 & $\begin{array}{l}\text { Minor bleeding from } \\
\text { implantation needle. Minor } \\
\text { bruising }\end{array}$ & $\begin{array}{l}\text { Not within tumor, } 1 \mathrm{~mm} \text { from } \\
\text { tumor edge }\end{array}$ & $\begin{array}{l}\text { Minimal fat necrosis, } \\
\text { macrophage infiltrate } \\
\text { immediately surrounding the } \\
\text { OxyChip }\end{array}$ \\
\hline 15 & 70 & $\mathrm{~F}$ & IDC & Left breast & Y & $\begin{array}{l}\text { Chemotherapy: } \\
\text { paclitaxel/ } \\
\text { trasuzumab } \times 3 \\
\text { cycles }\end{array}$ & 124 & 1 & $\begin{array}{l}\text { Mild discomfort from } \\
\text { implantation }\end{array}$ & $\begin{array}{l}\text { Uncertain relationship to } \\
\text { pre-treatment tumor }\end{array}$ & No histologic response seen \\
\hline 16 & 61 & $\mathrm{~F}$ & IDC & Left breast & Y & $\begin{array}{l}\text { Chemotherapy: } \\
\text { carboplatin/ } \\
\text { docetaxel/ } \\
\text { trastuzumab/ } \\
\text { pertuzumab } \times 6 \\
\text { cycles }\end{array}$ & 131 & 1 & $\begin{array}{l}\text { Mild discomfort and } \\
\text { bleeding from implantation } \\
\text { procedure. Bruising from } \\
\text { implantation needle. }\end{array}$ & $\begin{array}{l}\text { Uncertain relationship to } \\
\text { pre-treatment tumor }\end{array}$ & No histologic response seen \\
\hline 17 & 61 & $\mathrm{~F}$ & IDC & Left breast & Y & $\begin{array}{l}\text { Chemotherapy: } \\
\text { dose dense } \\
\text { adriamycin/cytoxan } \\
\times 4 \text { cycles }\end{array}$ & 137 & 1 & $\begin{array}{l}\text { Minor bleeding asociated } \\
\text { with implantation. Minor } \\
\text { bruising near needle } \\
\text { insertion site. Mild } \\
\text { discomfort of left breast, not } \\
\text { specifically associated with } \\
\text { area of implantation. }\end{array}$ & $\begin{array}{l}\text { Uncertain relationship to } \\
\text { pre-treatment tumor }\end{array}$ & No histologic response seen \\
\hline 18 & 23 & M & Sarcoma & Right chest wall & Y & $\begin{array}{l}\text { Radiotherapy: } 50 \\
\text { Gray }\end{array}$ & 78 & 1 & $\begin{array}{l}\text { Minor bleeding from } \\
\text { implantation needle }\end{array}$ & $\begin{array}{l}\text { Within collagenous soft } \\
\text { tissue skeletal muscle fascia } \\
\text { outside of viable tumor at } \\
\text { least } 6 \mathrm{~mm}\end{array}$ & No histologic response seen \\
\hline 19 & 51 & $\mathrm{~F}$ & IDC & Right breast & Y & $\begin{array}{l}\text { Chemotherapy: } \\
\text { carboplatin/ } \\
\text { docetaxel/ } \\
\text { trastuzumab/ } \\
\text { pertuzumab } \times 6 \\
\text { cycles }\end{array}$ & 125 & 1 & $\begin{array}{l}\text { Minor bleeding from } \\
\text { implantation needle }\end{array}$ & $\begin{array}{l}\text { Uncertain relationship to } \\
\text { pre-treatment tumor. } \\
\text { OxyChip not seen within } \\
\text { small foci of residual tumor. }\end{array}$ & $\begin{array}{l}\text { Focal fibrosis, a few } \\
\text { macrophages adjacent }\end{array}$ \\
\hline 20 & 55 & $\mathrm{~F}$ & IDC & Left axillary node & Y & $\begin{array}{l}\text { Chemotherapy: } \\
\text { dose dense } \\
\text { adriamycin } / \\
\text { cytoxan } \times 1 \text { cycle, } \\
\text { transitioned to } \\
\text { paclitaxel } \times 1 \\
\text { cycle }\end{array}$ & 138 & 0 & NA & $\begin{array}{l}\text { No residual } \\
\text { tumor-uncertain } \\
\text { relationship to pre-treatment } \\
\text { tumor }\end{array}$ & No histologic response seen \\
\hline
\end{tabular}




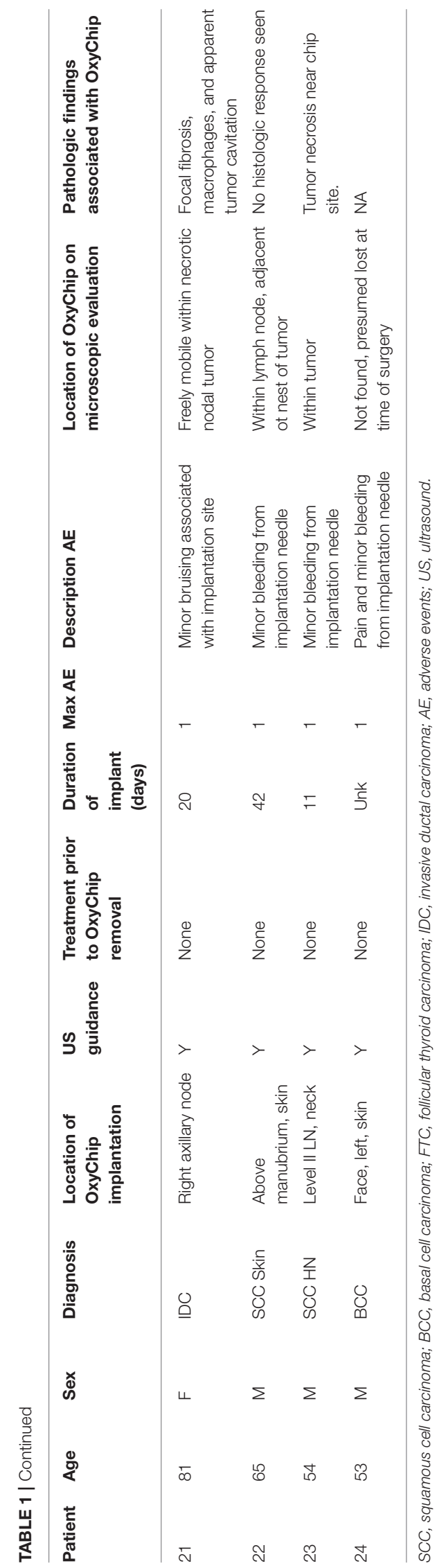

TABLE 2 | Patient-reported outcomes associated with implantation of the OxyChip and the experience of EPR oximetry.

\begin{tabular}{|c|c|c|}
\hline & Average score & Scale \\
\hline \multicolumn{3}{|c|}{ PRO with respect to the OxyChip implant } \\
\hline $\begin{array}{l}\text { How much pain did you feel the } \\
\text { day of the initial injection }\end{array}$ & 3 & $\begin{array}{l}\text { 1: Unbearable; 2: A lot; } \\
\text { 3: A little; 4: No pain }\end{array}$ \\
\hline At any time did you notice: & & $\begin{array}{l}\text { 1: Not at all; 2: A little; } \\
\text { 3: Quite a bit; 4: Very } \\
\text { much }\end{array}$ \\
\hline Swelling & 1 & \\
\hline Itching & 1 & \\
\hline Bleeding & 1.5 & \\
\hline Tenderness & 1.5 & \\
\hline Pain & 1.5 & \\
\hline Discharge & 1 & \\
\hline \multicolumn{3}{|c|}{ PRO with respect to the EPR oximetry measurement experience } \\
\hline $\begin{array}{l}\text { Please rate how comfortable you } \\
\text { felt: }\end{array}$ & & $\begin{array}{l}\text { Scale of } 1-5 \text { where } 1 \text { is } \\
\text { "Very Uncomfortable," } \\
3 \text { is "Neutral," } 5 \text { is "Very } \\
\text { Comfortable" }\end{array}$ \\
\hline Lying in the oximetry machine & 4 & \\
\hline Being confined in the machine & 4.5 & \\
\hline $\begin{array}{l}\text { During the measurement, did } \\
\text { you ever feel: }\end{array}$ & & $\begin{array}{l}\text { 1: Not at all; 2: A little; } \\
\text { 3: Quite a bit; 4: Very } \\
\text { much }\end{array}$ \\
\hline $\begin{array}{l}\text { Closed in, trapped, or unable to } \\
\text { get out }\end{array}$ & 1 & \\
\hline Pain or discomfort & 1.75 & \\
\hline $\begin{array}{l}\text { How would you rate the time it } \\
\text { took to complete the oximetry } \\
\text { measurement }\end{array}$ & 1 & $\begin{array}{l}\text { 1: Acceptable; 2: A little } \\
\text { too long; 3: Much too } \\
\text { Iong; 4: Unacceptable }\end{array}$ \\
\hline $\begin{array}{l}\text { How would you rate the following } \\
\text { in being measured by oximetry }\end{array}$ & & $\begin{array}{l}1-10 \text { scale, where } \\
1=\text { "Very Poor" and } \\
10=\text { "Very Good" }\end{array}$ \\
\hline Overall experience & 9.75 & \\
\hline Overall comfort & 9 & \\
\hline
\end{tabular}

surgical removal, gross evaluation of the tissue surrounding the OxyChip was performed. The integrity of the OxyChip, the OxyChip's placement relative to tumor margins, and the distance from the skin surface were assessed. The tissue surrounding the OxyChip was excised and sent for microscopic evaluation; a clinical pathologist assessed tissue findings associated with the OxyChip. The location of the OxyChip relative to microscopic tumor was described and was coded as within the tumor if malignant cells surrounded it; if no malignant cells encompassed the OxyChip, the distance to the closest malignant cell was noted. Adjacent microscopic tissue findings were described, graded in terms of their severity if abnormal, and categorized with respect to whether they were thought related to the implantation procedure and/or the OxyChip itself. They were further categorized as "anticipated" or "un-anticipated" based on expectations of normal tissue response to needle trauma and the presence of a foreign body (15). 


\section{RESULTS}

\section{Patient Population, Implantation Feasibility, and Success Rate}

Twenty-four patients were implanted with the OxyChip. The median age was 61 (range 23-83). Forty-six percent were women, and the majority of patients had either a squamous cell carcinoma of the skin $(33 \%)$ or an invasive ductal carcinoma of the breast (33\%) (Table 1). The median time from OxyChip implantation to surgical removal was 29 days (range 4-138). Of the 24 patients implanted, 18 received surgery alone as definitive care for their malignancy (median implant duration 21 days, range 442 days); five received chemotherapy prior to surgical resection (median implant duration 131 days, range 124-138 days); and one received radiotherapy prior to surgical resection (implant duration 78 days). In 12 patients, image guidance was not used for placement, initially as the protocol did not incorporate imaging, and later due to the superficiality and size of a number of the malignancies.

Of the patients implanted without image guidance who received surgery alone, at pathological analysis the OxyChip was found within the tumor in 8 of these 11 patients (73\%). Three OxyChips were found to be outside but adjacent to the tumor (Table 1, patients 1, 7, 10). In one patient implanted without image guidance, who had a squamous cell carcinoma of the skin, the OxyChip was found neither during EPR oximetry measurement attempts nor on pathologic assessment (Table 1, patient 6). This patient had a rapidly growing and necrotic tumor, which was undergoing daily dressing changes, and it was assumed that the OxyChip was inadvertently dislodged or fell out soon after implantation and prior to initiation of EPR oximetry. Of five patients implanted with image guidance who received surgery alone, four $(80 \%)$ of the OxyChips were found within the tumor (Table 1, patients 13, 21, 22, 23). In one patient with a basal cell carcinoma who received image-guided placement, the OxyChip was found during EPR oximetry measurements the day prior to surgery but was not found on pathologic assessment after surgical resection (Table 1, patient 24). This patient also had a progressive, necrotic tumor. In this patient, post-surgical MRI of the post-operative bed did not reveal the OxyChip, and it was assumed that the OxyChip had fallen out of the tumor between the last EPR measurement and surgery, or at the time of surgery. Of the five patients treated with neoadjuvant chemotherapy, all OxyChips were within the tumor on initial ultrasoundguided placement (Table 1, patients 15-17, 19, 20); however, determination of the location of the OxyChip relative to the tumor at pathological analysis was confounded by post-treatment effect (i.e., decrease in the size of or complete resolution of the tumor due to a partial or complete response to therapy). In one patient treated with neoadjuvant radiotherapy, the OxyChip was assessed to be within the tumor on initial ultrasoundguided placement (Table 1, patient 18); however, on pathology assessment it was found $6 \mathrm{~mm}$ outside the viable tumor. Overall, the OxyChip was definitively found inside the tumor in $50 \%$ of patients ( $n=12,8$ patients without US guidance, 4 patients with US guidance); it was definitively outside the tumor in $21 \%$ of patients ( $n=5,3$ patients without US guidance, 2 patients with
US guidance, one of whom received neoadjuvant radiotherapy prior to surgery); its position could not be interpreted due to treatment effect in $21 \%$ of patients $(n=5$, all patients with chemotherapy prior to surgery); it was not found in $8 \%$ of the patients $(n=2)$.

\section{Patient-Reported Outcomes and Adverse Events}

No serious unanticipated adverse events occurred. Most clinical adverse events were associated with initial OxyChip implantation. Adverse events noted around implantation were minor bleeding, bruising, and pain. Of these acute events, the maximal severity as graded by CTCAE 4.0 was 1 (i.e., "mild; asymptomatic or mild symptoms; clinical or diagnostic observations only; intervention not indicated"). In no patients were there any overlying skin changes (other than implantationassociated bruising) or signs of infection.

Four patients filled out the post-implantation questionnaire, administered after the first oximetry measurement session (Table 2). Of these, three had surgery alone and one had neoadjuvant chemotherapy. On average, patients rated the pain associated with the initial injection as "a little." Of the symptoms noted "at any time around the injection site," two patients rated bleeding as "a little," two patients noted "a little" tenderness, and two patients noted "a little" pain. For each of these questions, the other two patients responded "not at all." No patients described swelling, itching, or discharge. With respect to the experience of EPR measurements, all patients rated feeling not at all "closed in, trapped, or unable to get out" of the EPR scanner. Using a 1-10 scale where $10=$ "very good" and $1=$ "very poor," the "overall experience" of being measured within the EPR scanner averaged 9 , and the "overall comfort" also averaged 9.

\section{Pathologic Findings Associated With OxyChip Implantation}

After surgical resection of the tumor, microscopic findings demonstrated that 10 of 22 patients (45\%) had no histopathologic findings associated with the OxyChip. Expected changes associated with the process of implantation, including mild hemorrhage and minor inflammatory reactions at the needle site and surrounding the OxyChip, were present in 6 of 22 patients (27\%), all of whom had the OxyChip removed within $\sim 1$ month of injection (range 4-33 days) (Table 1, Figures 2, 3). In two patients where the OxyChip was not in tumor but in adjacent tissue, 0.4 and $0.1 \mathrm{~cm}$ from the tumor margin, respectively, focal fat necrosis was noted. In one patient, in whom the OxyChip was within a squamous cell carcinoma of the skin, a foreign body type giant cell reaction was noted. This finding was most consistent with a characteristic keratin foreign-body reaction in a disrupted squamous cell carcinoma. No associated tissue reactions on histopathology were found around the OxyChip in four of the five patients who had neoadjuvant chemotherapy (and only minor focal fibrosis, felt "unlikely" to be related to the OxyChip in the fifth patient), all of whom had the OxyChip implanted for greater than 120 days. Radiation fibrosis was evident in the patient who received prior radiotherapy, but no 
A

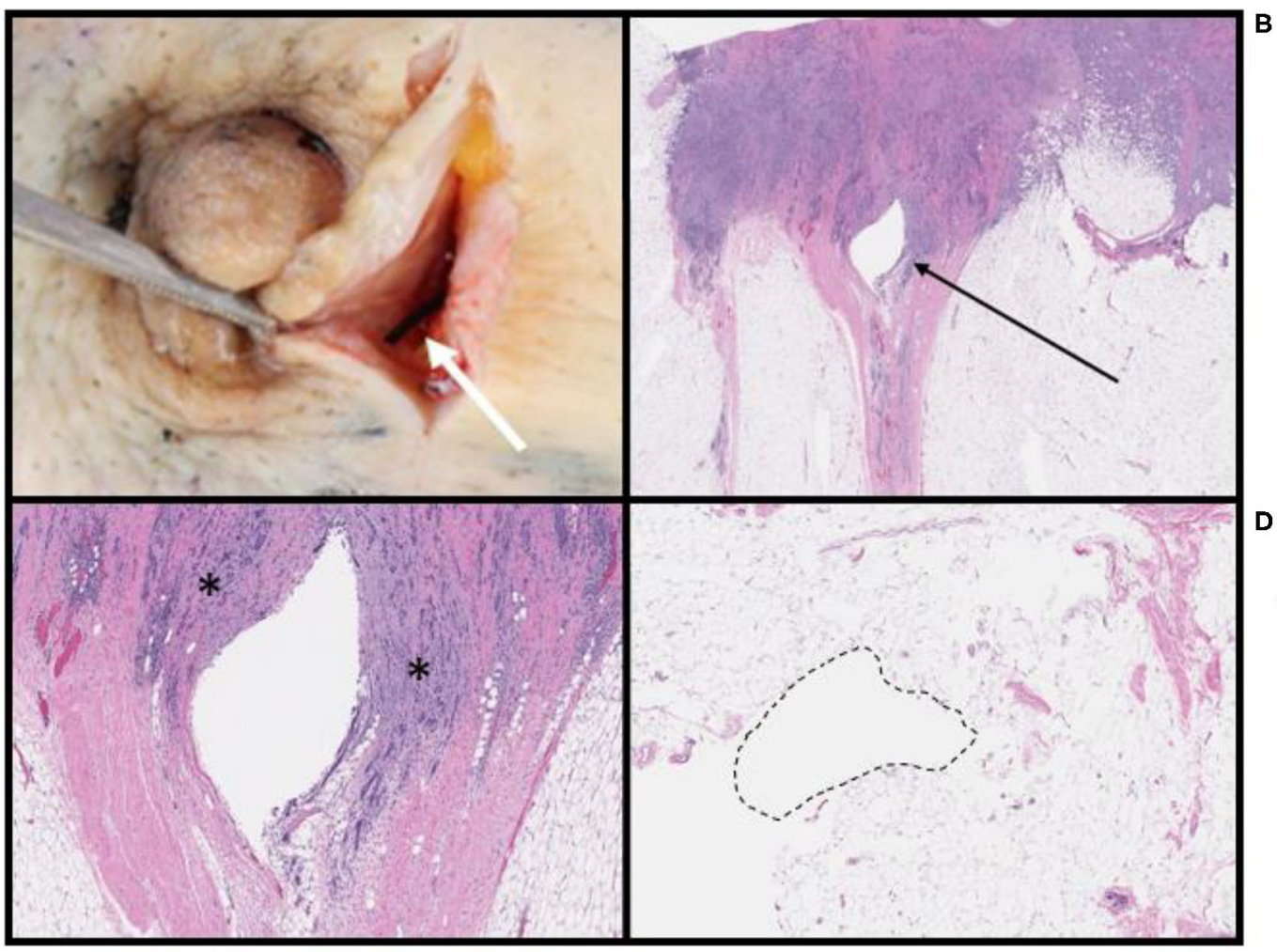

FIGURE 2 | Pathologic findings associated with OxyChip in invasive ductal carcinomas of the breast. (A) OxyChip in situ (white arrow) adjacent to the nipple within a gross specimen. (B) Low-power view of tissue surrounding the OxyChip defect (arrow); the patient received surgery alone 10 days after OxyChip placement. (C) High-power view of the same patient in (B). The OxyChip was present within the borders of invasive carcinoma (*). (D) Benign adipose tissue surrounding the OxyChip in a patient who received neoadjuvant chemotherapy followed by surgery. The OxyChip was in place for 131 days, and there is no definite evidence of tissue response or inflammation.

histologic response attributable to the OxyChip was noted. All pathologic findings were scored as "anticipated" except in a patient with an invasive ductal carcinoma of the breast, in which the OxyChip was implanted into an involved axillary lymph node. The OxyChip in this patient ended up in a cystic core with associated fibrosis and inflammation surrounding this area. As the focal fibrosis/inflammation was deemed more than typical, it was scored as "unanticipated;" however, the histopathologic changes were felt to be a function of the tumor and a heightened immune response secondary to the lymph node site rather than the implantation procedure or the OxyChip itself.

\section{DISCUSSION}

Despite numerous clinical trials investigating hypoxia modification concurrent with anti-neoplastic therapies, hypoxia modification has not yielded a consistent benefit that has translated to routine clinical use. Data strongly indicate that in some circumstances, such as radiotherapy for head and neck cancer, hypoxia modification has the potential to significantly improve oncologic outcomes $(6,16)$. However, clinical implementation of hypoxia modification even in the most promising circumstances has been hampered by an inability to (i) appropriately identify patients with hypoxic malignancies, (ii) assess whether each individual patient's malignancy will respond to hypoxia modification (and if so, to what type of hypoxia modification), and (iii) reassess the tumoral response to hypoxia modification during treatment (allowing for alteration and adjustment of hypoxia modification during therapy). In short, in the absence of a technique to meet the noted needs, clinical implementation of hypoxia modification has not entered the era of precision medicine. Individualized treatment is likely integral to successful, consistent improvement in oncologic outcomes. Furthermore, these assessments and interventions need to be feasible in the clinic in order to be integrated with current standard-of-care therapies.

The OxyChip has the potential to significantly contribute to the individualization of hypoxia modification therapy in that it can facilitate rapid, repeatable assessment of absolute tumoral $\mathrm{pO}_{2}$ in the clinic prior to and during oncologic therapies. In this initial clinical trial, its use was found to be safe and clinically feasible. Of the 24 patients implanted with the OxyChip, no adverse events greater than Grade 1 were noted, and all were associated with the initial minimally invasive implantation procedure. Patient-reported outcomes indicated that the overall process of implantation and measurement was well-tolerated, 
$\mathbf{A}$

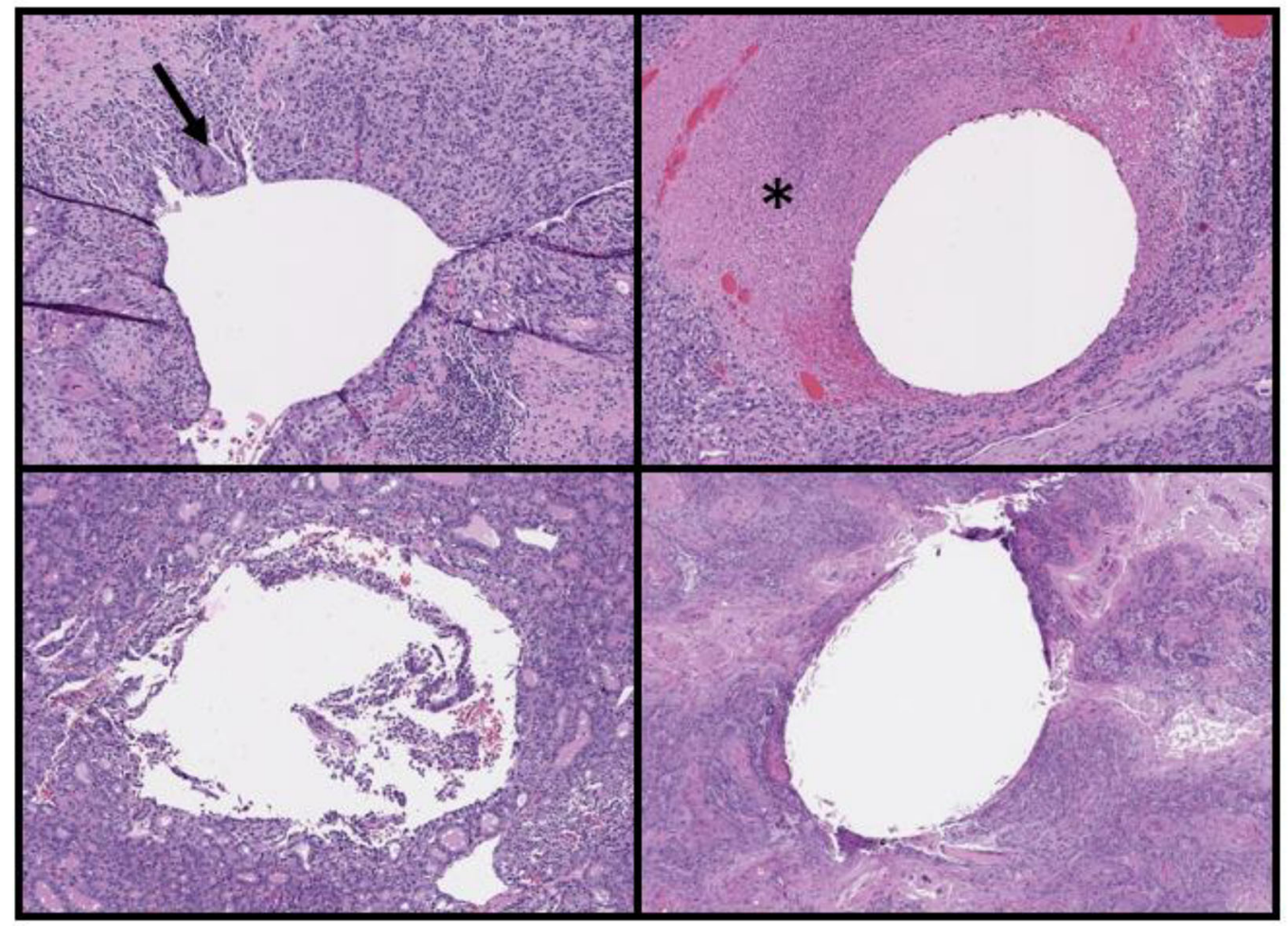

FIGURE 3 | Pathologic findings associated with the OxyChip in non-breast malignancies. (A) Tissue surrounding the OxyChip in a patient with a squamous cell carcinoma (SCC) of the left nasal skin, including associated foreign body giant cells (arrow), likely due to tumor keratin reaction at the site of injection. (B) Tissue surrounding the OxyChip in a patient with a melanoma of the scalp, including peritumoral injection-related tumor necrosis (*). (C) Tissue surrounding the OxyChip in a patient with a follicular thyroid cancer, showing no identifiable tissue response. (D) Tissue surrounding the OxyChip in a patient with an SCC of the frontal scalp, showing no identifiable tissue response.

although the number of patients who agreed to participate in this portion of the trial was small. On microscopic assessment of tissue adjacent to the OxyChip, 45\% of specimens had no associated histopathology, and on those specimens that had associated histopathologic changes, all were consistent with the mild inflammation expected with implantation trauma and the presence of a foreign body or tumor-related histopathology. In only one patient was there an "unanticipated" degree of necrosis and inflammation, but these findings were felt to be a function of the tumor and not the implantation procedure or the OxyChip itself. Importantly, four of six long-term implantations (range 78-138 days) had no histopathologic reaction to the OxyChip, and in the other two implantations, only focal, minor fibrosis was present. These data indicate that the process of implantation and measurement was well-tolerated with minimal risk and that tissue reactions to the presence of the OxyChip appeared to be within expectations.

Localization of the OxyChip to the area of interest (i.e., the tumor itself) is critical to the success of targeted hypoxia assessment. It would be clearly desirable to have a high degree of confidence (i) that the OxyChip will be placed within the tumor and (ii) that its location can be easily verified once placement has occurred. In the current trial, in patients who received surgery alone, placement was achieved with an $80 \%(n=5)$ to $73 \%$
( $n=11)$ success rate, with and without imaging, respectively. It was not possible to definitively assess whether placement was within the tumor in patients who received neoadjuvant chemotherapy or radiation therapy due to treatment response, although at the time of OxyChip deployment it appeared to be within the tumor in all cases. Although ultrasound guidance did not appear to significantly increase the likelihood of intratumoral placement, it is important to note that in general, ultrasound guidance was used for deeper tumors that were not easily assessed on physical exam; the rate of successful placement is likely to have been much lower without ultrasound guidance in these patients. Given clear experiential technical advantages with ultrasound, we continue to use it for assistance with placement in almost all enrolled patients.

In order to maximize the probability of placement within the tumor, patient selection is also important. Although no minimum size criteria was mandated for enrollment earlier in the trial, in order to minimize the risk of placement outside of tumor currently the minimum size of eligible tumors is $2.5 \mathrm{~cm}$. The size of the OxyChip, at $0.5 \mathrm{~cm}$ in length, associated with potential uncertainty even with image-guided placement, likely contributed to challenges with deployment into smaller tumors. At this point in the evolution of this technology, however, retrieval of the OxyChip has been 
necessary in order to appropriately investigate device safety, and smaller sizes were felt to present challenges vis a vis this need. Future iterations of the OxyChip may include smaller probes, thereby diminishing the impact of size on accuracy of deployment. Other considerations impact the decision to use differently sized OxyChips, most prominently the issue of hypoxia heterogeneity within a given tumor. Heterogeneity of oxygenation within tumors is a complex issue, as it can vary spatially and temporally and is influenced by underlying pathology as well as anti-neoplastic therapies (17). The OxyChip has unique advantages in terms of assessing temporal changes in hypoxia via EPR oximetry, as the $\mathrm{pO}_{2}$ can be repeated measured non-invasively as often as desired, but the measurement is limited to the small volume of tissue surrounding the OxyChip. The use of multiple, smaller OxyChips deployed within different regions of the tumor is an area of investigation, and may provide greater insight into spatially heterogeneous hypoxia.

The clinical relevance of this approach is dependent on successful placement and detection of the OxyChip, and the procedural modifications that have developed over the course of the protocol (e.g., patient selection, use of ultrasound imaging) are expected to increase the likelihood of accurate placement in future trials. Regarding the potential "loss" of OxyChips (i.e., implants not found at the time of pathology), it is difficult to draw conclusions from the two patients in whom the OxyChip was not found due to sample size. However, both patients had superficial, ulcerated skin malignancies, and the OxyChip was placed in viable tumor at the edge of the necrotic area. Based on this experience, it seems reasonable to be cautious about implantations in necrotic, superficial malignancies due to the risk of progressive necrosis and potential loss of the OxyChip. Currently, the OxyChip is not radio-opaque and is also difficult to visualize by ultrasound. It is thus challenging to quickly image the OxyChip prior to or during surgery to confirm its presence and location. In order to mitigate the possibility of OxyChip loss in the future, current efforts are undergoing to modify the OxyChip to increase the sensitivity of routine radiographic and ultrasound imaging.

Current investigational strategies for clinical assessment of tumor hypoxia, and potential hypoxia modification, are beyond the scope of this article and have been reviewed recently $(18,19)$. Of the strategies that directly measure $\mathrm{pO}_{2}$ in tissue, including polarographic electrodes, sensors relying on fluorescence quenching, and EPR oximetry, only EPR oximetry allows repeated measurements in deeper tissues over time in a non-invasive and clinically feasible fashion. The capability to obtain clinically straightforward, repeated measurements over the course of clinical care, interrogating hypoxia both with and without any oxygen modification, is likely to be a necessary component of a successful program of individualized hypoxia modification. The OxyChip device appears to help meet this need, and, as reported here, early data indicate that its use in humans is safe and feasible. Future efforts are focusing on continued assessment of device safety, with the goal of permanent implantation, utilization of pre-implantation hypoxia assessment to facilitate directed OxyChip placement into known areas of hypoxia, and alteration of the number of implantations (and the size of the OxyChip) to increase the yield of information on the spatial heterogeneity of tumor hypoxia. Data from hypoxia measurements in this trial, and the results of hypoxia modification using EPR oximetry with OxyChip, will be reported in a separate publication; it was felt that the extent and complexity of that data would be best served by devoting a single publication to its analysis and that the primary endpoint (safety and efficacy) should be reviewed in depth separately.

\section{CONCLUSION}

This report of the first-in-humans trial of OxyChip implantation followed by EPR oximetry demonstrated no significant clinical adverse effects. The implantation procedure and the process of EPR oximetry in the clinic were well-tolerated by patients. Histopathologic findings revealed no clinically significant pathology, indicating that the tissue reaction to the OxyChip was well within expectations for an implanted device. Use of the OxyChip in the clinic was thus safe and well-tolerated by patients.

\section{DATA AVAILABILITY STATEMENT}

The raw data supporting the conclusions of this article will be made available by the authors, without undue reservation.

\section{ETHICS STATEMENT}

The studies involving human participants were reviewed and approved by The Institutional Review Boards at Dartmouth College and Dartmouth-Hitchcock Medical Center. The patients/participants provided their written informed consent to participate in this study.

\section{AUTHOR CONTRIBUTIONS}

AF, PS, HS, and PK conceived and designed analysis and wrote the paper. BW, PS, PK, HS, JP, LJ, EC, DP, RZ, and Rd-A contributed data or analysis. PS, AF, and JP performed the analysis. All authors contributed to the article and approved the submitted version.

\section{FUNDING}

This study was supported by National Institutes of Health Grant Numbers P01 CA190193 and R01 EB004031.

\section{ACKNOWLEDGMENTS}

The authors would like to acknowledge Robyn Mosher, MS, for manuscript editing and preparation, as well as Victoria Wood, Benoit Gosselin, Christina Angeles, and all of the patients who participated in the study. 


\section{REFERENCES}

1. Muz B, de la Puente P, Azab F, Azab AK. The role of hypoxia in cancer progression, angiogenesis, metastasis, and resistance to therapy. Hypoxia. (2015) 3:83-92. doi: 10.2147/HP.S93413

2. Semenza GL. The hypoxic tumor microenvironment: a driving force for breast cancer progression. Biochim Biophys Acta-Mol Cell Res. (2016) 1863:382-91. doi: 10.1016/j.bbamcr.2015.05.036

3. Nyström H, Jönsson M, Werner-Hartman L, Nilbert M, Carneiro A. Hypoxia-inducible factor $1 \alpha$ predicts recurrence in high-grade soft tissue sarcoma of extremities and trunk wall. J Clin Pathol. (2017) 70:879-85. doi: 10.1136/jclinpath-2016-204149

4. Nys K, Maes H, Dudek AM, Agostinis P. Uncovering the role of hypoxia inducible factor- $1 \alpha$ in skin carcinogenesis. Biochim Biophys Acta Rev Cancer. (2011) 1816:1-12. doi: 10.1016/j.bbcan.2011.02.001

5. Bedogni B, Powell MB. Hypoxia, melanocytes and melanoma-survival and tumor development in the permissive microenvironment of the skin. Pigment Cell Melanoma Res. (2009) 22:166-74. doi: 10.1111/j.1755-148X.2009.00553.x

6. Overgaard J. Hypoxic modification of radiotherapy in squamous cell carcinoma of the head and neck-a systematic review and meta-analysis. Radiother Oncol. (2011) 100:22-32. doi: 10.1016/j.radonc.2011.03.004

7. Janssens GO, Rademakers SE, Terhaard CH, Doornaert PA, Bijl HP, van den Ende P, et al. Accelerated radiotherapy with carbogen and nicotinamide for laryngeal cancer: results of a phase III randomized trial. J Clin Oncol. (2012) 30:1777-83. doi: 10.1200/JCO.2011.35.9315

8. Swartz HM, Williams BB, Zaki BI, Hartford AC, Jarvis LA, Chen EY, et al. Clinical EPR: unique opportunities and some challenges. Acad Radiol. (2014) 21:197-206. doi: 10.1016/j.acra.2013.10.011

9. Swartz HM, Hou H, Khan N, Jarvis LA, Chen EY, Williams BB, et al. Advances in probes and methods for clinical EPR oximetry. Adv Exp Med Biol. (2014) 812:73-9. doi: 10.1007/978-1-4939-0620-8_10

10. Williams BB, Khan N, Zaki B, Hartford A, Ernstoff MS, Swartz HM. Clinical electron paramagnetic resonance (EPR) oximetry using India ink. Adv Exp Med Biol. (2010) 662:149-56. doi: 10.1007/978-1-4419-1241-1_21

11. Flood AB, Wood VA, Swartz HM. Using India ink as a sensor for oximetry: evidence of its safety as a medical device. Adv Exp Med Biol. (2017) 977:297312. doi: 10.1007/978-3-319-55231-6_40

12. Kmiec MM, Tse D, Mast JM, Ahmad R, Kuppusamy P. Implantable microchip containing oxygen-sensing paramagnetic crystals for long-term, repeated, and multisite in vivo oximetry. Biomed Microdevices. (2019) 21:71. doi: 10.1007/s10544-019-0421-x
13. Hou H, Khan N, Gohain S, Kuppusamy ML, Kuppusamy P. Pre-clinical evaluation of OxyChip for long-term EPR oximetry. Biomed Microdevices. (2018) 20:29. doi: 10.1007/s10544-018-0272-x

14. Cancer Institute N. Common Terminology Criteria for Adverse Events (CTCAE) Version 4.0. (2009). Available online at: http://www.meddramsso. com (accessed January 12, 2020).

15. Patil S, Rao RS, Ganavi BS. A foreigner in squamous cell carcinoma! J Int Oral Heal JIOH. (2013) 5:147-50.

16. Horsman MR, Overgaard J. The impact of hypoxia and its modification of the outcome of radiotherapy. J Radiat Res. (2016) 57:i90-8. doi: 10.1093/jrr/rrw007

17. Swartz HM, Flood AB, Schaner PE, Halpern H, Williams BB, Pogue BW, et al. How best to interpret measures of levels of oxygen in tissues to make them effective clinical tools for care of patients with cancer and other oxygen-dependent pathologies. Physiol Rep. (2020) 8:e14541. doi: 10.14814/phy2.14541

18. Flood AB, Satinsky VA, Swartz HM. Comparing the effectiveness of methods to measure oxygen in tissues for prognosis and treatment of cancer. Adv Exp Med Biol. (2016) 923:113-20. doi: 10.1007/978-3-319-38810-6_15

19. Colliez F, Gallez B, Jordan BF. Assessing tumor oxygenation for predicting outcome in radiation oncology: a review of studies correlating tumor hypoxic status and outcome in the preclinical and clinical settings. Front Oncol. (2017) 7:10. doi: 10.3389/fonc.2017.00010

Conflict of Interest: AF and HS report part ownership of Clin-EPR, LLC, during the conduct of the study; Clin-EPR manufactures EPR instruments for investigational use only. PK reports that he has a patent issued for OxyChip, but received no compensation.

The remaining authors declare that the research was conducted in the absence of any commercial or financial relationships that could be construed as a potential conflict of interest.

Copyright (C) 2020 Schaner, Pettus, Flood, Williams, Jarvis, Chen, Pastel, Zuurbier, diFlorio-Alexander, Swartz and Kuppusamy. This is an open-access article distributed under the terms of the Creative Commons Attribution License (CC BY). The use, distribution or reproduction in other forums is permitted, provided the original author(s) and the copyright owner(s) are credited and that the original publication in this journal is cited, in accordance with accepted academic practice. No use, distribution or reproduction is permitted which does not comply with these terms. 